ние трудоспособности больных, перенесших ожоги, возможно только при условии четкой организации реабилитационных мероприятий. Однако до сих пор нет единой общепринятой системы организации дальнейшего лечения пострацавших от ож огов после их выписки из ожогового отделения. Назрела необходимость организации отделений или центров реабилитации для проведения восстановительного лечения при крупных ожоговых центрах или учреждениях ортопедо-травматологического профиля.

Необходимо подчеркнуть, что залогом успешной реабилитации обожженных явяется пунктуальное выполнение основных принципов профилактики послеож оговых цеформаций и контрактур, а именно: раннее и рациональное оперативное лечение ожоговых ран, правильное положение и соответствующая фиксация сустава в сочетании с лечебной гимнастикой.

\title{
ЛИТЕРАТУРА
}

1. Ожоги (Руководство для врачей). Под ред. Б. С. Вихриева, В. М. Вурмистрова.- Л., Медицина, 1986.- 2. Федорова Г. П., Печатникова Е. А.//Клин. хир.- 1972. № 8. С. 4 8.- 3. Коенич B. В., Гришкевич B. М.//Руководство по реабилитации обожженных.- М., 1986.-4. Olney D. B.//Hand.-1983.- Vol. 15.— P. 179-184.

Поступила 09.07.87.

УдК $616-001.186-08$

\section{ПРОБЛЕМЫ ЛЕЧЕНИЯ ОТМОРОЖЕНИЙ}

\author{
В. С. Вихриев, С. Х. Кичемасов, Ю. Р. Сквориов
}

Кафедра термических поражений (начальник-проф. Б. С. Вихриев) Военно-медицинской академии имени С. М. Кирова, Ленинград

Механизм патологических изменений, развивающихся в тканях при отморожениях, многообразен и варьирует в очень широких пределах не только при различных формах локальных поражений (от действия сухого холода, «траншейная» и. «иммерсионная» стопа, контактные отморожения), но и в разных участках поражения у одного и того же пострадавшего. Вероятно, патогенез отморожений в различных климатических регионах также несходен.

Первичное криоповреждение тканей достаточно хорошо изучено. Оно наиболее вероятно при контактных отморожениях. Можно предположить, что аналогичное поражение возможно и при изредка встречающемся оледенении конечностей. Однако неизвестно, что происходит при этой разновидности отморожений: только образование ледяной корки либо действительное промерзание тканей. В большинстве случаев температура тканей остается выше $0^{\circ}$, при которой жизнь клеток вне организма возможна, Литературные данные свидетельствуют о том, что критическая точка криоповреждения тканей лежит в диапазоне от - $4^{\circ}$ до-10 Наши исследования показали, что кровоток в магистральных артериях лап кроликов прекращается при тканевой температуре от-2० до-3, а некроз тканей наступает после их охлаждения до - $10^{\circ}$. Однако в условиях сохранения анатомической связи с организмом ткани человека гибнут и после менее выраженного охлаждения.

Правомочно рассматривать отморожение как защитную реакцию на локальное охлаждение, предупреждающую развитие опасной общей гипотермии. Различные сосудистые реакции при локальном охлаждении конечностей препятствуют поступлению из них охлажденной крови в общий кровоток. После кратковременного рефлекторного спазма наблюдается расширение периферических сосудов (гиперемия конечностей). При продолжающемся охлаждении пойкилотермное «ядро» повторным спазмом сосудов «отключает» гомейотермную периферию. В первую очередь нарушается венозный отток, осуществляющийся в основном по подкожным венам. При сохранившемся артериальном притоке происходит переполнение кровеносного русла форменными элементами крови. Микроциркуляция прекращается при тканевой температуре значительно выше $0^{\circ}$, хотя обменные процессы в тканях еще продолжаются. Наступает ишемия периферических тканей. Таким образом, жертвуя своей частью (конечностями), организм спасает себя как целое. Эти процессы протекают в периоде тканевой гипотермии.

В реактивном периоде охлажденные сегменты согреваются в основном от внешнего источника тепла, причем в первую очередь повышаются температура 
и интенсивность обменных процессов в клетках поверхностно расположенных тканей. Однако растущий клеточный метаболизм не обеспечивается адекватным восстановлением кровоснабжения через сосуды, проходящие в глубоких, еще не прогревшихся слоях. Клетки гибнут из-за недостаточного снабжения кислородом и удаления продуктов тканевого обмена. После восстановления кровообращения пострадавшие ткани становятся источником поступления в кровоток веществ, являющихся продуктами распада клеток. На этом этапе наряду с сосудистыми реакциями включается еще один защитный механизм - тромбоз сосудов пострадавшего сегмента.

Такое представление о патогенезе отморожений не лишено схематизма. Тем не менее его правомочность подтверждается и существующими в настоящее время методами циагностики глубины поражения, в подавляющем большинстве основанными на оценке расстройств кровообращения. Хотя в дореактивном периоде расстройства кровообрацения выражены максимально, методов диагностики на данном этапе нет. Это связано, с одной стороны, с высокой обратимостью местных процессов, с другой - с их зависимостью от рациональной первой помощи и последующего консервативного лечения. Поэтому в дореактивном и реактивном периодах оценивать глубину отморожения принципиально неверно. Можно лишь судить о тяжести холодовой травмы, основанной на совокупности факторов, способствующих или препятствующих охлаждению тканей.

Существуюшие инструментальные методы диагностики отморожений (ангиография, гаммасцинтиграфия, термография) дают достаточно точную информацию не ранее 2-3 сут после травмы. Возможно, более информативна инфракрасная термография, однако для этого необходима сложная аппаратура. Обнадеживающие результаты показало экспериментальное и клиническое применение прижизненных тканевых красителей. Так, димифен голубой позволил нам довольно точно установить зоны стойкого расстройства кровообращения у животных сразу после согревания тканей, а у человека - через 8-10 часов. Вместе с тем нельзя сбрасывать со счетов клиническую диагностику, правильная трактовка которой в сочетании с анамнестическими данными может быть информативна в самые первые часы реактивного периода.

До сих пор камнем преткновения остается оказание первой помощи в дореактивном периоде. Погружение охлажденных сегментов конечностей в холодную воду или снег, растирание их снегом, интенсивное разминание и грубый массаж в настояшее время полностью отвергнуты. Идеальным вариантом было бы максимально быстрое восстановление тканевой температуры с обеспечением всего охлажденного сегмента адекватным кровообращением. Существующие в настоящее время два диаметрально противоположных способа - согревание в теплой воде и теплоизоляция - не отвечают одновременно обоим требованиям. В теплой воде наблюдается относительно быстрое прогревание тканей, но оно начинается от периферических и поверхностных участков, в которых кровообращение восстанавливается только после прогревания более глубоких отделов, на что необходимо определенное время. В такой ситуации «оживающие» согретые ткани гибнут от усугубляющейся ишемии вследствие необеспеченности полноценным кровоснабжением.

В условиях изоляции от внешнего согревания теоретически восстановление кровообращения и тканевой температуры идет параллельно из глубины. Однако в этом случае согревание всего сегмента затягивается на несколько часов, что может отрицательно сказаться на тканях, страдавших от гипоксии в период охлаждения. Кроме того, наши экспериментальные исследования показали, что температура, при которой восстанавливается артериальный кровоток после охлаждения, в большой степени зависит от уровня исходной тканевой гипотермии: чем ниже данный уровень, тем более высокая температура тканей требуется для восстановления кровотока. Приведенные факты свидетельствуют не в пользу метода теплоизоляции.

В дореактивном периоде в лечебные учреждения доставляется лишь незначительное число пострадавших. Так, в этом периоде в нашу клинику поступили лишь $13 \%$ больных, через 6 ч после травмы - 30\%, 12 ч - 40\%, к исходу первых суток и позднее - $60 \%$.

В настоящее время всеобщее признание получила консервативная терапия отморожений, направленная на восстановление периферического кровообращения путем ликвидации сосудистого спазма, улучшения реологических свойств крови, предупреждения тромбоза сосудов. В нашей клинике с 1980 г. внедрена схема лечения, включающая введение (в сутки) 40-60 тыс. ед. гепарина, 40 тыс. ед. 
фибринолизина, 800 мл низкомолекулярных декстранов (реополиглюкин, реохем), растворов глюкозы и новокаина малой концентрации, дезагрегантов (аспирин, трентал), сосудорасширяющих средств (но-шпа, папаверин, никотиновая кислота, компламин, ацетилхолин) и др. Инфузионная терапия продолжается почти непрерывно в течение 4-5 дней. Опыт ее использования у 49 больных показал, что существенного эффекта удается достичь, если лечение начато не позднее первых суток после травмы. Чтобы ликвидировать сосудистый спазм, сосудорасширяюшие средства целесообразно вводить в артерии пораженных конечностей путем их чрескожной пункции. Наилучшие результаты наблюдаются при длительном внутриартериальном введении всех указанных средств. С этой целью производится катетеризация магистральных артерий конечностей через их второстепенные ветви. Для нижних конечностей возможна катетеризация аорты.

Остается спорной целесообразность использования гепарина. В результате лечения 24 больных по указанной выше схеме без гепарина и фибринолизина было установлено, что уменьшить распространение некроза удается при такой терапии, которая начата в первые $6-12$ ч реактивного периода.

В лечении отморожений определенные надежды возлагались на гипербарическую оксигенацию. Наш опыт ее применения у 66 больных показал, что в ранние сроки после травмы она целесообразна в сочетании с инфузионно-антикоагулянтной терапией. В более поздние сроки ее эффект сводится к ускорению эпителизации при поверхностных или мумификации некроза при глубоких отморожениях. Значительно ускоряют мумификацию погибших участков и сокращают сроки их подготовки к ампутации локальные абактериальные изоляторы, с успехом использованные нами у 62 больных.

Принципы оперативного лечения глубоких отморожений, сформулированные T. Я. Арьевым более 50 лет тому назад, предусматривают последовательное выполнение ряда вмешательств. Некротомия производится на 3-7-е сутки для перевода влажного некроза в сухой. Некрэктомия - вычленение пораженного сегмента в суставе дистальнее линии демаркации - осуществляется на 7-10-е сутки для ликвидации острого воспаления и подготовки конечности к ампутации. Последняя должна обеспечивать получение пригодной к протезированию культи. Такой тактики придерживаются при поражении крупных сегментов конечностей, когда имеет место выраженная интоксикация продуктами распада и высока вероятность развития инфекционных осложнений.

Благодаря значительному развитию кожно-пластической хирургии сформировался сберегательно-восстановительный подход к оперативному лечению глубоких отморожений. Он предусматривает максимальную длину и функциональную активность культи пораженного сегмента конечности, что достигается сохранением всего непораженного костного сегмента, восстановлением полноценного кожного покрова, созданием условий для выполнения последующих реконструктивно-восстановительных вмешательств.

Ампутация сегмента конечности с усечением жизнеспособной кости выше линии демаркации мягких тканей всегда ведет к укорочению получаемой культи, поэтому она не может быть рекомендована для широкого применения. Последнее относится и к дерматомной пластике ран торцов культей, позволяющей сохранять длинную, но функционально неполноценную культю. Оптимальным является создание на торце культи полноценного кожного покрова, что достигается использованием как относительно простых, так и самых сложных методов кожной пластики. Выбор способа замещения образующейся раны культи определяется, с одной стороны, многообразием различных методов кожной пластики, с другой возможностями данного лечебного учреждения.

При глубоких отморожениях пальцев кистей на уровне ногтевых и средних фаланг может быть осуществлена ампутация с ушиванием раны. Однако, как показал опыт выполнения операций на 211 пальцах, более рационально закрытие раны на торце культи перемещением островковых треугольных лоскутов. При поражении на уровне основных фаланг достаточно эффективна итальянская пластика лоскутами, выкроенными на плече, предплечье, передней брюшной стенке. Более перспективна пластика паховым лоскутом на временной питающей ножке, особенно при тренировке лоскута по специальной методике, позволяющей отсекать его от донорского ложа через 5 сут после первого этапа пластики.

При отморожении IV степени пальцев стоп с учетом их меньшей функциональной значимости возможна ампутация с ушиванием ран или пластика островковым треугольным лоскутом. При отморожении более проксимальных сегментов возникающее неизбежно укорочение культи стопы, а значит, и площади опоры также требует максимально щадящего оперативного вмешательства. Важным 
фактором при выборе уровня ампутации становится граница жизнеспособной кожи подошвы. При целостности кожи на тыле стопы наиболее приемлемый вариант закрытия раны - перемещение мостовидного лоскута с тыла стопы. При дефиците мягких тканей нужны более сложные, но перспективные методыгіластика островковыми кожно-фасциальными лоскутами голени на дистальной сосудистой ножке (с ретроградным кровотоком) или свободная пересадка кожножирового лоскута с анастомозированием сосудов лоскута и стопы, а также со швом нервов. При ограниченных дефектах пяточной области наиболее эффективна пластика островковыми лоскутами на сосудисто-нервной ножке, выкроенными на тыле или в области внутреннего свода стопы.

Не потеряла своего значения итальянская пластика с противоположной конечности, однако иммобилизация при такой пластике крайне мучительна для больного.

Как отчаянную попытку сохранения пальцев при глубоких отморожениях кисти следует рассматривать операцию, предложенную А. А. Карпушиным. Она основана на представлении о том, что костная и фиброзная ткани обладают наиболее высокой устойчивостью к охлаждению. Не позднее 6 - 8 ч после прекращения действия холода выполняется скелетирование палыцев кисти с сохранением костно-суставного и сухожильного аппарата и вшивание их под кожу живота. В последующем осуществляется поэтапное разделение и формирование пальцев. Несмотря на определенную перспективность, этот метод лечения многоэтапен и требует длительного времени. Для рекомендации такой тактики лечения к широкому внедрению необходимо дальнейшее накопление клинических наблюдений.

Большая часть больных, перенесших отморожение кистей IV степени, становятся инвалидами и нуждаются в дальнейшем в реконструктивно-восстановительных вмешательствах, направленных на улучшение функции кисти. Пострадавшим с культями голеней и стоп необходимо индивидуальное протезирование. Это предъявляет серьезные требования к протезно-ортопедическим предприятиям и учреждениям, а также диктует необходимость разработки хирургами и ортопедами единой согласованной доктрины оперативного лечения глубоких отморожений.

Поступила 26.05.87.

УДК $616-001.186$

\title{
ОСТРАЯ ХОЛОДОВАЯ ТРАВМА
}

\author{
Н. Р. Панченков
}

Центральный научно-исследовательский институт гематологии и переливания крови МЗ СССР, Москва

Острая холодовая травма, несмотря на возрастающую комфортность быта и труда, остается довольно частой не только в северных и горных районах нашей страны, но и в средней полосе $[9,12,14]$. Высокий процент инвалидности перенесших отморожения III-IV степени дает основание считать острую холодовую травму проблемой не только медицинской, но и социально-экономической.

Среди наиболее частых причин отморожений и общего охлаждения остается длительное пребывание на холоде лиц в состоянии алкогольного опьянения. По нашим наблюдениям, в $1977-1984$ гг. процент поступивших в стационар в состоянии алкогольного опьянения колебался от 85 до 95; в 1985-1987 гг. он снизился до $70-80$, но в то же время уменьшилось и число пострадавших, госпитализированных в дореактивном периоде. Это в определенной мере можно объяснить тем, что лица с отморожением в состоянии опьянения предпочитают не обращатья за медицинской помощью.

Следующую группу больных, получивших отморожения в бытовых условиях, составляют лица преимущественно в возрасте $14-20$ лет, занимающиеся зимними видами спорта (лыжный туризм, занятия бегом и игра в футбол при низкой температуре окружающей среды).

В производственных условиях отморожения в основном кистей рук получают водители автотранспорта. Пытаясь ликвидировать возникшие неисправности, они подвергают кисти рук переохлаждению при контакте с охлажденным металлом, топливом, что и вызывает отморожения. Даже непродолжительная экспозиция охлажденного до температуры окружающей среды топлива ведет к очень 